\title{
A RARE CASE OF ANATOMICAL VARIATION OF THE FEMORAL ARTERY AND VEIN
}

\author{
Ba $B_{1}$, Touré $T_{1}$, Kanté $A_{1}$, 2, Koné $M_{1}$, Kouamenou $K D_{1}$, Koné $M_{1}$, Guissé $F_{3}$, Coulibaly $T_{3}$, Ongoïba $N_{1,2}$, Koumaré \\ AK 1 \\ 1) Anatomy laboratory of the Faculty of Medicine and Odontostomatology of Bamako, Mali \\ 2) Surgery Department B of the Point-G University Hospital Center, Bamako, Mali \\ 3) Trauma Department of the Gabriel Touré University Hospital Center, Bamako, Mali \\ Correspondence to Ba Habou Baye dit Babou, Anatomy laboratory of the Faculty of Medicine and \\ Odontostomatology of Bamako, BP : 1805, Email : babaouba20022000@yahoo.frCell : 66756860/ \\ 76756860
}

\begin{abstract}
During a dissection of the two femoral trigons in a female corpse, about 14 years old, we discovered on the right side, the deep artery of the thigh arising from the medial side of the femoral artery and passed in front of the femoral vein above the mouth of the great saphenous vein; on both sides, there was the presence of a collateral canal which communicated the external iliac vein with the femoral vein on the right, on the left, it communicated the external iliac vein with the quadricipital vein. The lower part of the femoral vein was duplicated on both sides, but on the right, there was an interconnecting channel between the two trunks of the duplication. Variations of the femoral vessels are very frequent and can be responsible for an incident during the practice of certain gestures at the level of the femoral trigon such as: catheterization of the femoral artery or vein, the treatment of femoral hernias.
\end{abstract}

Key words: Deep thigh artery, collateral venous canal, external iliac vein, anatomic variations.

\section{INTRODUCTION}

The femoral artery is the continuation of the external iliac artery. It is located at the anteromedial (anteromedial) part of the thigh and extends from the femoral arch (inguinal ligament) to the ring of the third adductor (the hiatus of the adductor) where it becomes the popliteal artery (Rouvière and Delmas 1991). In the femoral trigone, the femoral artery (FA) gives five superficial branches which are: the superficial iliac circumflex artery, the superficial epigastric artery, the two external pudendal arteries and the deep thigh artery (DFA). The latter is the most voluminous of the collateral branches of the femoral artery, it originates from the posterior surface of the femoral artery

The femoral vein (FV) follows the popliteal vein and ends at the femoral ring, through the external iliac vein. It receives two tributary veins, the great saphenous vein and the deep femoral vein (Kamina P, 2009). At the level of the femoral trigone, the initial part of the femoral artery is used for a number of clinical methods. Catheterization of the femoral artery can be performed for angiocardiography of the left heart or for coronary angiography [Dixit et al., 2011]. It is used for the establishment of circuits of the extracorporeal circulation (Kamina P, 2009). The femoral vein is used clinically for catheterization of the femoral vein for angiography of the right heart; for temporary hemodialysis for the venous line; for emergency venous infusions requiring a large caliber venous route and easy access even in case of collapse.

A few cases of the deep thigh artery arising from the medial aspect and passing in front of the femoral vein have been reported in the literature, but a collateral venous canal connecting the femoral vein and the external iliac vein has not been reported in Literature. 


\section{RESULTS}

During an anatomical dissection of the two femoral trigons in a female corpse, about 14 years old, we discovered a rare anatomical variation of the femoral artery on the right side and a rare anatomical variation of the femoral vein of the two sides.

On the right side, the DFA originated from the medial aspect of the FA at a distance of 1.3 $\mathrm{mm}$ from the inguinal ligament and passed in front of the FV just above the mouth of the great saphenous vein, then bypassed the medial side of the FV to pass behind the latter before engaging between the pectineal and long adductor muscles (Figure 1, right side). The DFA gave birth to two collateral branches that went to the pectineal muscle. Its usual collateral branches originated directly from the FA; the medial circumflex artery originated in a common trunk with the superficial iliac circumflex artery of the posterior aspect of the FA before the birth of the DFA; the quadricipital artery was two in number, one originated by a common trunk with the lateral circumflex artery of the thigh of FA before the birth of DFA, the other took FA after birth of the DFA. At the upper part of the femoral trigone, the $\mathrm{AF}$ was located laterally with respect to the FV; at the lower part of the femoral trigone, the femoral artery was located in front and inside of the FV.

On the left side, the DFA originated from the posterior aspect of the FA $40 \mathrm{~mm}$ from the inguinal ligament. It gave birth by a common trunk to the lateral circumflex artery of the thigh and to the artery of the quadriceps. FA gave birth to the medial circumflex artery of the thigh and an artery for the pectineal muscle which passed behind the FV.

On the right side, there was the presence of a $4 \mathrm{~mm}$ diameter collateral venous canal which communicated the FV and the external iliac vein. This collateral canal was located outside the artery of the femoral artery and received the deep iliac circumflex vein above the inguinal ligament. It passed in front of the external iliac artery before blending into the external iliac vein. The FV was duplicated at its lower part, the two trunks were arranged on each side of the FA, one, lateral which had a diameter of $6 \mathrm{~mm}$ and the other, medial which had a diameter of $4 \mathrm{~mm}$. The latter in turn was divided into two branches, one of which (considered as an interconnection channel) passed in front of the FA before joining the lateral trunk before the delivery of the deep femoral vein and the another was delivered in the femoral vein downstream of the delivery of the deep femoral vein. Downstream of the delivery of the deep femoral vein, in addition to the second branch of the medial trunk of the duplication, the FV received the great saphenous vein, the circumflex femoral veins and muscular veins. The FV at its termination had a diameter of $14 \mathrm{~mm}$.

On the left side, there was also the presence of a collateral canal which had a diameter of 2 $\mathrm{mm}$, also located outside the FA, but which communicated the quadricipital vein and the external iliac vein. This lateral channel received by its lateral side muscular veins coming from the quadriceps below the inguinal ligament and the deep iliac circumflex vein above the inguinal ligament and was connected to the FV by a few interconnection branches which passed behind the FV. Like the one on the right side, it passed in front of the external iliac artery before reaching the external iliac vein above the inguinal ligament. The FV was duplicated at its bottom, one of the two trunks had a diameter of $2 \mathrm{~mm}$, the other had a diameter of $5 \mathrm{~mm}$. The diameter of the FV was $12 \mathrm{~mm}$ at its end bet. 

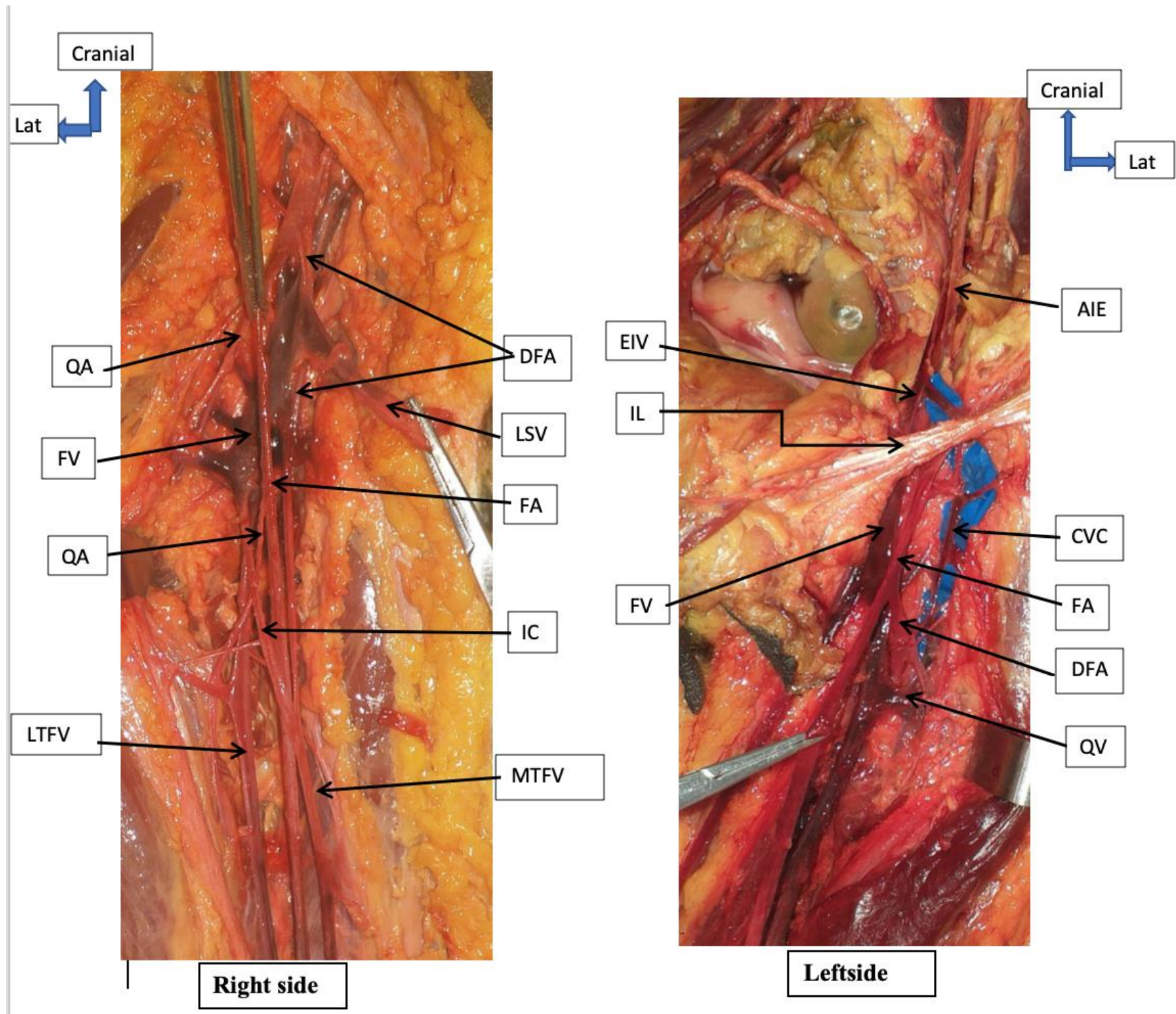

Figure 1: Right side: DFA passed in front of the femoral vein and the duplicated and interconnected femoral vein ;Left side: collateral venous canal communicating the VQ and the EIV. CVC=Collateral venous canal, DFA=Deep femoral artery, $E I A=$ External iliac artery, EIV=External iliac vein, FA=Femoral artery, FV=Femoral vein, IC=Interconnexionchanal, $I L=$ Inguinal ligament, $\angle S V=L a r g e$ saphenous vein, $\angle T V F D=L a t e r a l$ trunk of the duplicated femoral vein, MTVFD=Medial trunk of duplicated femoral vein, $Q A=$ Quadricipital artery, $Q V=Q u a d r i c i p i t a l$ vein

\section{DISCUSSION}

Deep femoral artery arising from the medial aspect of the FA and passing in front of the FV is rare in the literature. (Rajani SJ et al., 2015) observed this variation in the two limbs on a dissection of 33 corpses, ie $3.03 \%$. This same variation has been reported (Chitra $R, 2008$; Johnston TB, 1912; Lipshutz BB, 1916; Siddharth et al., 1985). It was observed by (Sahin and Bilgic, 1998) in 1\% of dissections of 100 lower limbs. Such a variation can lead to a risk of damage to the large and unexpected arterial canal during blood collection in infants from the femoral vein and during the exposure of the arch of the large vein for the ligature of its junction with the femoral vein [Daksha D. 2011]. It has been reported that cases of arteriovenous fistulas can occur in the groin area as a complication of percutaneous angioplasty or cardiac catheterization of the femoral vessels (Chitra R, 2008).

Prior to catheterization of the femoral vessels and operations in the femoral trigone, high resolution ultrasound imaging can provide anatomical and functional information on the femoral vessels and would be useful in planning catheterization (Canale., 1982). This knowledge is also essential in the repair of femoral hernias (Johnston TB, 1912). A 
collateral venous canal connecting the femoral vein and the external iliac vein has not been described in the literature. This may be responsible for asymptomatic venous thrombosis when the thrombus is located at the proximal part of the femoral vein with respect to its junction with the collateral canal. A duplicated and interconnected femoral vein, similar to our case, on the right side has been reported by (Khan AA et al., 2013). The prevalence of duplicated femoral veins is variable, ranging from $12 \%$ to $46 \%$, depending on the technique used: anatomical study, venography or ultrasound (Uhl JF et al., 2010).

It has been described by doctors, radiologists, a relationship between the presence of multiple femoral veins and the occurrence of deep vein thrombosis [Liu GC. 1986] performed ascending positive contrast venography on 337 lower limbs to determine if anatomical variations predisposed to DVT and to explain why so many patients with DVT were asymptomatic. They found several femoral veins in $31 \%$ of the limbs. $40 \%$ of members with multiple femoral veins had DVT. This was a statistically higher incidence $(P<0.001)$ than that seen in the $19 \%$ of these members with a single femoral vein. They concluded that one of the factors responsible for "silent" DVT is the presence of multiple femoral veins.

Duplicated femoral veins can be a source of error in the ultrasound investigation of deep vein thrombosis. (Screaton et al., .1998), after a retrospective analysis on 381 venograms, found false negatives in four (2\%) of 204 patients with single femoral veins and in 10 $(6 \%)$ of 117 patients with duplicated femoral veins ( $p=0.056$, not statistically significant). They concluded that the frequency of proximal thrombosis missed on ultrasound appears to be increased in the presence of duplicated superficial femoral veins.

In conclusion, the variations of the femoral vessels are very frequent and can be responsible for an incident during the practice of certain gestures at the level of the femoral trigon such as: catheterization of the artery or of the femoral vein, the treatment of femoral hernias.

\section{REFERENCES}

1. Canale JM, Lange L, Friedman MJ. 1982. A new technique for noninvasive evaluation of femoral arterial and venous anatomy before and after percutaneous cardiac catheterization in children and infants. Am J Cardiol 49:349-355.

2. Chitra R.2008 May. A rare variational anatomy of the profundafemorisartery. FoliaMorphol(Warsz) 67(2): 157-8.

3. Daksha Dixit, KubavatDharati $M$, Rathod Suresh Bhai $P$, Patel Mittal $M$, Single Tulsi Bhai C.2011.A study of variation in origin of profunda femoris artery and its circumflex branches.Int J Biol Med Res 2(4):1084-89.

4. Johnston TB. 1912. A rare anomaly of the arteria profunda femoris. AnatAnz 42: 269-272.

5. Kamina P. 2009. Precis d'anatomie clinique anatomie générale, organogénèse des membres.Tome 1 membre supérieure membre inférieur.Paris:Maloine.

6. Khan AA, Hassan A, Asari MA, Aiman N. 2013.An interconnected duplicated femoral vein and its clinical significance.Folia Morphol 72(1):82-85.

7. Lipshutz BB.1916. Study on the blood vascular tree I.A composite study of the femoral artery. Anat Rec 10:361-370.

8. Liu GC, Ferris EJ, Reifsteck JR, Baker ME. 1986. Effect of anatomic variations on deep vein thrombosis of the lower extremity. An J Roentgenol 146:845-848.

9. Moore KL, Dalley AF. 2007. Medical anatomy: fundamental aspects and clinical applications (DhemA\&Milaire J, Trad. 5th ed). Paris: De Boeck.

10. Rajani SJ, Ravat MK, Rajani JK, Bhedi AN. 2015.Cadaveric Study of Profunda Femoris Artery with Some Unique Variations. J ClinDiagnRes 9(5):AC01-AC3. doi: $10.7860 / J C D R / 2015 / 13913.5876$. 
11. Rouvière H, Delmas A. 1991. Viasseaux du membre inférieur. In:Anatomie humaine descriptive, topographique et fonctionnelle. Tome III Membres, système nerveux central. Treizième edition révisée et augmentée. Paris:Masson, p 443-468.

12. Sahin B, Bilgic S.1998.Two rare arterial variations of the deep femoral artery in the newborn.SurgRadiol Anat 20: 233-235.

13. Screaton NJ, Gillard JH, Berman LH, Kemp PM.1998.Duplicated superficial femoral vein: a source of error in the sonographic investigation of deep vein thrombosis. Radilogy 206(2): 397-401.

14. Siddharth P, Smith NL, Mason RA, Giron F.1985.Variational anatomy of the deep femoral artery.AnatRec 212: 206-209.

15. Uhl JF, Gillot C, Chalim M. 2010. Anatomical variations of the femoral vein. J VascSurg 52(3):714-9. 